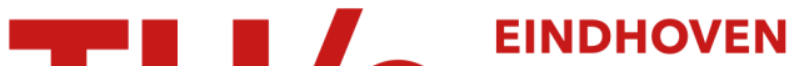

\section{Determination of safety stocks in a lost sales inventory system with periodic review, positive lead-time, lot-sizing and a target fill rate}

\section{Citation for published version (APA):}

Donselaar, van, K. H., \& Broekmeulen, R. A. C. M. (2010). Determination of safety stocks in a lost sales inventory system with periodic review, positive lead-time, lot-sizing and a target fill rate. (BETA publicatie : working papers; Vol. 336). Technische Universiteit Eindhoven.

\section{Document status and date:}

Published: 01/11/2010

\section{Document Version:}

Publisher's PDF, also known as Version of Record (includes final page, issue and volume numbers)

\section{Please check the document version of this publication:}

- A submitted manuscript is the version of the article upon submission and before peer-review. There can be important differences between the submitted version and the official published version of record. People interested in the research are advised to contact the author for the final version of the publication, or visit the DOI to the publisher's website.

- The final author version and the galley proof are versions of the publication after peer review.

- The final published version features the final layout of the paper including the volume, issue and page numbers.

Link to publication

\footnotetext{
General rights

- You may freely distribute the URL identifying the publication in the public portal. follow below link for the End User Agreement:

www.tue.nl/taverne

Take down policy

If you believe that this document breaches copyright please contact us at:

openaccess@tue.nl

providing details and we will investigate your claim.
}

Copyright and moral rights for the publications made accessible in the public portal are retained by the authors and/or other copyright owners and it is a condition of accessing publications that users recognise and abide by the legal requirements associated with these rights.

- Users may download and print one copy of any publication from the public portal for the purpose of private study or research.

- You may not further distribute the material or use it for any profit-making activity or commercial gain

If the publication is distributed under the terms of Article $25 \mathrm{fa}$ of the Dutch Copyright Act, indicated by the "Taverne" license above, please 


\title{
Beta
}

Research School for Operations

Management and Logistics

Determination Of Safety Stocks In A Lost Sales Inventory System

With Periodic Review, Positive Lead-Time, Lot-Sizing And A Target Fill Rate

\author{
K.H. van Donselaar, R.A.C.M. Broekmeulen
}

Beta Working Paper series 336

\begin{tabular}{|rl|}
\hline BETA publicatie & WP 336 (working \\
ISBN & paper) \\
ISSN & \\
NUR & \\
Eindhoven & November 2010 \\
\hline
\end{tabular}




\title{
Determination Of Safety Stocks In A Lost Sales Inventory System With Periodic Review, Positive Lead-Time, Lot- Sizing And A Target Fill Rate
}

\author{
by Karel H. van Donselaar ${ }^{a}$ and Rob A.C.M. Broekmeulen ${ }^{a}$ \\ ${ }^{a}$ Eindhoven University of Technology, Department of Industrial Engineering \& Innovation \\ Sciences, Paviljoen room E3, P.O. Box 513, 5600 MB Eindhoven, The Netherlands, \\ k.h.v.donselaar@tue.nl and r.a.c.m.broekmeulen@tue.nl
}

corresponding author: Karel van Donselaar, Eindhoven University of Technology, Dept. IE\&IS, The Netherlands, tel.0031-40-2472869, k.h.v.donselaar@tue.nl.

\begin{abstract}
An approximation for the fill rate, i.e. the percentage of demand being delivered from inventory on hand immediately, is derived for items in a periodic review inventory control system with lost sales. We assume demand is stochastic and discrete, lead times are positive and replenishments are made in multiples of a given fixed case pack size. Most literature on inventory control systems assumes that unmet demand is backordered. The major reason for this is that the analysis of a general lost sales inventory system is known to be hard. To find an approximation for the fill rate, given a safety stock, we start with existing analytical approximations. By applying linear regression, we slightly modify these existing approximations. The new approximation is tested for a wide set of parameters and performs very well: the average approximation error for the fill rate is only $0.28 \%$ and the standard deviation of the approximation error is $0.45 \%$. Since the approximations are very fast, this result enables inventory controllers dealing with a lost sales inventory system to set safety stocks in accordance with the target service level set by their management in an effective way. The results of our study also show that the assumption that the lost sales system can simply be approximated by a
\end{abstract}


backordering system if the target fill rate is at least $95 \%$, may lead to serious approximation errors.

\section{Keywords}

(B) Inventory; Lost sales; Safety stock; Fill Rate ; Approximation;

\section{Introduction}

Many inventory systems in practice are confronted with lost sales if demand can not be delivered instantaneously from inventory on hand. In a worldwide survey on out-of-stocks in the fast moving consumer goods retail sector for example, Gruen et al. (2002) show that only $15 \%$ of all customers delay the purchase if they are faced with a stock-out for their preferred product in a particular store. The other $85 \%$ of the customers decide to buy another product (substitution), buy the product in another store or not buy the product at all. In all these cases demand for the preferred product-store combination is lost.

While lost sales systems are very relevant in practice, most scientific papers on stochastic inventory models assume backordering. The reason for the limited attention for lost sales systems in the scientific literature is the fact that discrete-time inventory models with stochastic demands, a constant lead-time and lost sales are notoriously difficult (Zipkin, 2008). The first structural results were derived by Karlin and Scarf (1958) and Morton (1969). In contrast to the case with backordering, where the optimal reorder quantity can be derived from a single number (the sum of the inventory on hand and on order), in case of lost sales the optimal reorder quantity is a function of the inventory on hand as well the timing and quantity of all outstanding orders. As a result, the state space increases rapidly as the lead-time increases.

For an extensive and recent review of the literature on lost sales systems we refer to Bijvank (2009). He classifies the literature in four categories: continuous review systems with fixed or variable order sizes (referred to as $(\mathrm{s}, \mathrm{Q})$ and $(\mathrm{s}, \mathrm{S})$ policies) and periodic review systems without and with fixed order costs. His literature review confirms that there are only a limited number of papers dealing with lost sales systems and the vast majority of these papers make simplifying assumptions to make them analytically tractable. Out of the 57 papers he identified, 18 papers study continuous review systems with a fixed order size and the majority of these papers (13 papers) assume at most 1 (or 2) orders are outstanding, while four other papers 
assume lead-time and/or demand have a specific probability distribution function (e.g. Poisson). Likewise, out of the nine papers on continuous review systems with variable order sizes, i.e. $(\mathrm{s}, \mathrm{S})$-order-up-to policies, seven papers assume $\mathrm{s}=\mathrm{S}-1$. The majority of the 30 papers on periodic review systems assume there are no fixed order costs (24 papers) and out of the remaining 6 papers only one paper, by Johansen and Hill (2000), deals with fixed order sizes. Their paper assumes that at most one order is outstanding, which limits its applicability.

Another observation from this literature review is the fact that in the majority of the 57 papers on lost sales systems the objective is to minimise costs, while only eight papers are based on a minimal service restriction. These eight papers are: Hadley and Whitin (1963), Mohebbi and Posner (1998), Hill (1992, 1994), Aardal et al. (1989), Tijms and Groenevelt (1984), Van Donselaar et al. (1996) and Kapalka et al. (1999). Very recently, an approximation for the fill rate service criterion in a lost sales system with a (R,s,nQ)-policy was derived, which was developed and tested for an environment with perishable items having relatively small leadtimes, small case pack sizes and low demand uncertainty (Van Donselaar and Broekmeulen, 2009). Bijvank (2009, p. 57-58) claims that adding a minimal service restriction to an inventory model with lost sales makes the model more realistic to represent a retail environment, but also makes the analysis and computations more difficult. He then compares the (R,s,nQ)-policy with the optimal policy in a periodic review setting with a service level constraint for a wide set of inventory systems and concludes that the (R,s,nQ)-policy is close to optimal (around $0.3 \%$ deviation), but that there is a need for a good approximation procedure to set the control parameters. Recently Zipkin (2008) evaluated base stock policies in lost sales systems and identified specific areas where they are more than $5 \%$ from optimal: if the lot-size is very small (the ratio between case pack size and average demand per review period was equal to 0.2 in his experiments), the penalty costs for lost sales are low and the lead-time is large. If these three conditions are met simultaneously, it is suggested to apply one of the other policies investigated by Zipkin.

Our paper is the first paper studying for a wide set of product- and demand-parameters the determination of the reorder level in a lost sales system with a (R,s,nQ)-policy in a periodic review setting with a service level constraint. We derive and test an approximation for the fill rate as a function of the safety stock and a fixed case pack size (often determined by an external supplier). Based on the literature we first identify two constructs of variables having a large 
impact on the performance of lost sales systems. Next we study the behavior of three currently existing approximations for the fill rate in lost sales systems as a function of these constructs of variables. Finally we use linear regression and the constructs of variables to improve the current approximations. Ehrhardt (1979, 1984) and Schneider and Ringuest (1990) also applied linear regression to set reorder levels, but did this for periodic review inventory systems with backordering and (s,S)-policies. Berling and Marklund (2006) also used linear regression in the context of inventory control systems. They used this technique to get an approximation for the induced backorder costs in a one-warehouse multiple-retailer system.

We compare the performance of the new approximation with the current approximations and show that the new approximation performs very well: the average and standard deviation of the approximation error is below $0.5 \%$. Since the approximations are very fast, this result enables inventory controllers dealing with a lost sales inventory system to set safety stocks in accordance with the target service level set by their management in an effective way.

The structure of this paper is as follows. In Section 2 the model assumptions and notation are introduced. Section 3 introduces and evaluates three currently existing approximations. The new approximation is developed and tested in Section 4. Section 5 gives the conclusions of this paper and suggestions for future research.

\section{Model assumptions and notation}

We study a single echelon inventory system having a positive lead time $L$, a review period $R$, a fixed case pack size $Q$ and stochastic discrete demand per period with mean $\mu$ and variance $\sigma^{2}$. Demand which is not met from stock is lost.

In the model, the sequence of events during a period is as follows: first demand is subtracted from the inventory during the period, performance measures such as the service level are calculated, goods arrive, and finally the orders are placed.

The reorder policy is a simple (R,s,nQ)-policy; if at a review moment the inventory position drops below the reorder level s, an integer multiple of case packs each with fixed size Q units are ordered in order to raise the inventory position back to or above s. The reorder level $s$ is equal to $s=(L+R) \mu+s s$, with ss denoting the safety stock. The service level of the 
inventory system is measured via the service level $P_{2}$, also known as the fill rate. The fill rate is defined as the percentage of demand which can be satisfied from the inventory on hand immediately.

To evaluate the quality of the approximations to be derived in this paper, we simulated a very large number of inventory systems by changing all six system-parameters in a systematic way: the average demand, the variance to mean ratio for the demand, the case pack size, the leadtime, the review period and the safety stock. Table 1 shows which values were attributed to these parameters. These values are in line with the values in the design of experiments by Bijvank (2009). For example, Bijvank used the values 2, 5 and 10 for the average demand and varied the variance to mean ratio from 1 to 3.5 (depending on the demand distribution used). We use the same average demand, but also include lower and higher variance to mean ratios (in line with Johansen and Hill (2000), who also included experiments with low demand uncertainty). For the discrete demand distribution we used the fitting procedure of Adan et al. (1995), which includes the binomial, negative binomial, Poisson and geometric distribution. Bijvank assumed a (compound) Poisson or negative binomial distribution. To further enlarge the design of experiments, also inventory systems with very small case pack sizes (including the lot-for-lot policy and fixed case pack sizes which are equal to the average demand per period) and large lead-times were added, in line with Nahmias (1979) who varied the lead-time from 5 to 10 and 20 periods.

For every combination of parameter values we varied the safety stock, starting at value zero and increasing it in steps of 1 unit until a fill rate of 99\% was passed. This implies that our experimental design also includes experiments with a low fill rate (51.3\%) as well as experiments with a very high fill rate (99.95\%). Bijvank (2009) targeted for a minimum fill rate equal to $85 \%, 90 \%$ and $95 \%$. By varying all parameters in this way (including the safety stock) we have 12544 simulation experiments in total. Based on the guidelines in Law and Kelton (2000), per simulation experiment we performed at least 10 replications, each consisting of 350 periods as the warming-up periods and ending with 7000 periods in which the statistics are recorded. We replicated until we reached an absolute precision for the fill rate $P_{2} \pm 0.002$ with $95 \%$ confidence.

Please put Table 1 here. 


\section{Three current approximations}

The new approximation for the fill rate in a lost sales inventory system to be developed in this paper is an extension of and improvement on currently existing approximations. Therefore we first introduce three current approximations and show their performance, based on the design of experiments described in the previous section. Based on their performance, we argue how their performance can be improved, leading to the new approximation.

The simplest approximation is based on the assumption that the performance of the lost sales system is equal to the performance of the backorder system which is identical to the lost sales system on all aspects except for the fact that demand which cannot be delivered from inventory on hand is backordered instead of being lost. This approximation is called P2BO. As argued by Silver et al. (1998, p.234), this is a reasonable approximation if the customer service level is high.

The approximation for the fill rate in a lost sales system $\left(\hat{P}_{2}^{L S}\right)$ is then simply equal to the fill rate for the backorder system:

$$
\hat{P}_{2}^{L S}=P_{2}^{B O}
$$

An improvement on this approximation is suggested by Silver et al. (1998, pages 268 and 300 ; also mentioned in $2^{\text {nd }}$ edition of 1985) for the continuous review lost sales system with $(\mathrm{s}, \mathrm{Q})$ policy and by Tijms and Groenevelt (1984) for the (s,S)-policy . They suggest to approximate the fill rate in a lost sales system $\left(\hat{P}_{2}^{L S}\right)$ by using the following equation:

$$
\frac{1-\hat{P}_{2}^{L S}}{\hat{P}_{2}^{L S}}=1-P_{2}^{B O}
$$

Recently, Van Donselaar and Broekmeulen (2009) introduced an iterative procedure to determine the fill rate in a lost sales system. In each iteration the fill rate for a lost sales system with stochastic demand $D$ is set equal to the fill rate in a backordering system with stochastic demand equal to $D^{\prime}$, where the mean and variance of $D^{\prime}$ are equal to the mean and variance of $D$ times the fill rate for the lost sales system determined in the previous iteration. In the first iteration $D^{\prime}$ is set equal to $D$. The fill rate in the i-th iteration is then determined as follows:

$$
1-\hat{P}_{2, i+1}^{L S}(\ldots, D, \ldots)=1-P_{2}^{B O}\left(\ldots, D_{i}^{\prime}, \ldots\right)
$$


All these three current approximations are based on the fill rate in the backorder system. Van Donselaar and Broekmeulen (2009) derived the following formula for the fill rate in a backorder system with a (R,s,nQ) replenishment logic and with discrete stochastic demand:

$$
\begin{aligned}
1- & P_{2}^{B O}=\frac{E\left[\left(D_{L+R}-\Delta-(s-1)\right)^{+}\right]-E\left[\left(D_{L}-\Delta-(s-1)\right)^{+}\right]}{\mu_{R}} \\
= & \frac{1}{Q \mu_{R}}\left[\sum_{i=1}^{Q} \sum_{d=i+s}^{\infty}(d-i-s+1) P\left(D_{L+R}=d\right)-\sum_{i=1}^{Q} \sum_{d=i+s}^{\infty}(d-i-s+1) P\left(D_{L}=d\right)\right]
\end{aligned}
$$

with $D_{L+R}$ representing the demand during the lead-time plus review period and $\Delta$ a discrete stochastic variable uniformly distributed between 1 and Q.

The third approximation has been tested only for parameter settings which are typical for perishable products, e.g. small case pack sizes and small lead times. Therefore we first evaluate the performance of the three approximations using the design of experiments introduced in the previous section. Figure 1 shows the performance of the first approximation, which is based on the assumption that the lost sales system behaves in the same way as the backordering system. For a given safety stock the fill rate in the lost sales system (according to the simulation) is given on the horizontal axis and on the vertical axis the fill rate for the backorder system is given. The fill rate in the lost sales system is always at least as high as in the backorder system, but sometimes the difference gets very large, for example when the fill rate in the backorder system is below $60 \%$ while the fill rate in the lost sales system exceeds $90 \%$. The service level in the lost sales system for a given safety stock is always at least as high as the service level in the backordering system, since the actual sales per period in a lost sales system (equal to $P_{2}^{L S} \mu$ ) are less than the actual sales in a backordering system (equal to $\mu$ ). So with the same amount of inventory in the system, due to lower sales the same or a higher service level can be achieved in the lost sales system.

Figure 2 shows the performance of the second and the third approximation, which from here on are referred to as P2Silv and P2DoBr.

Please put Figure 1 here.

Please put Figure 2 here. 
To evaluate the performance of these approximations, we calculate the average and the standard deviation of the approximation error. The approximation error is equal to the fill rate based on simulation (P2LS) minus the approximated fill rate. The results in Table 2 show that the approximation of Van Donselaar and Broekmeulen performs best, but still has an average error equal to $2.1 \%$ with a standard deviation equal to $1.8 \%$.

Please put Table 2 here.

Since in most practical situations the target fill rate is high, Table 3 also shows the performance of the three approximations for the subset of experiments where the fill rate in the simulated lost sales system is equal to or above $95 \%$. Although the average errors are lower, they are still substantial. Especially note that when the backordering approximation is used (P2BO), the average error is equal to $3.8 \%$. This shows that even when the target fill rate is high, serious errors can be made when a lost sales system is approximated by a backordering system.

Please put Table 3 here.

\section{The new approximation}

In order to develop a new approximation, we first identify two constructs of variables having a large impact on the performance of lost sales systems. Next we study the behavior of the current approximations for the fill rate in lost sales systems (introduced in the previous Section) as a function of these constructs of variables. Finally we use linear regression and the constructs of variables to improve the current approximations.

Two important factors to take into account when the fill rate of a lost sales system is determined are the extent to which the demand during the lead-time plus review period is uncertain and the number of orders outstanding. The first can be easily measured via the coefficient of variation of the demand during the lead-time plus review period which, in case demand is identically and independently distributed, is simply equal to:

$$
c_{L+R}=\frac{\sigma}{\mu \sqrt{L+R}}
$$


Already in 1963, Hadley and Whitin (p. 197) noted that for the lost sales system it is necessary to take explicit account of the number of orders outstanding and the times at which they were placed. The simplest single measure to take into account the number of outstanding orders is the variable $n O O$, which is defined as the ratio between the expected demand during the lead-time $(L \mu)$ and a simple proxy for the expected order size $(\max (Q ; R \mu))$ :

$$
n O O=\frac{L \mu}{\max (Q ; R \mu)}
$$

To illustrate how important indeed these two variables are in explaining the fill rate of the lost sales system, we show again Figures 1 and 2 but now for a specific value of $c_{L+R}(=0,707)$ and for a specific value of $n O O(=4)$. Figure 3 shows that for a specific value of $c_{L+R}$ the relationship between the fill rate for a lost sales system and its three approximations is much clearer than for an unspecified value of $c_{L+R}$. Especially the relationship between P2BO and P2LS is close to linear for this specific value of $c_{L+R}$. Figure 4 shows that especially for the third approximation, $\mathrm{P} 2 \mathrm{DoBr}$, the relationship between $\mathrm{P} 2 \mathrm{DoBr}$ and $\mathrm{P} 2 \mathrm{LS}$ is close to linear for a specific value of $n O O(=4)$.

Please put Figure 3 here.

Please put Figure 4 here.

Having observed that a close-to-linear relationship exists between P2LS and P2DoBr for given values of $n O O$ as well as between P2LS and P2BO for given values of $c_{L+R}$, we will use linear regression to estimate the coefficients $\alpha, \alpha^{\prime}, \beta$ and $\beta^{\prime}$ in the following two relationships:

$$
\begin{aligned}
& P 2 D o B r=\alpha(n O O)+\beta(n O O) P 2 L S \\
& P 2 B O=\alpha^{\prime}\left(c_{L+R}\right)+\beta^{\prime}\left(c_{L+R}\right) P 2 L S
\end{aligned}
$$

The coefficients $\alpha$ and $\beta$ (resp. $\alpha^{\prime}$ and $\beta^{\prime}$ ) are determined via OLS regression on the simulations results for all experiments having the same value for $n O O$ (resp. $c_{L+R}$ ). Therefore 
these coefficients are a function of $n O O$ (resp. $c_{L+R}$ ), as expressed in equations (5) and (6). The first step now is to determine the value of the coefficients $\alpha$ and $\beta$ for specific values of $n O O\left(\operatorname{resp} . c_{L+R}\right)$.

Table 4 shows the results of regression analyses between P2LS and P2DoBr for different values of $n O O$, reporting the coefficients $\alpha(n O O)$ and $\beta(n O O)$ as well as the $\mathrm{R}^{2}$-adjusted.

Please put Table 4 here.

Table 4 clearly shows that for $n O O<5$ the $\mathrm{R}^{2}$-adjusted is close to $99 \%$, implying a relationship between P2LS and P2DoBr which is close to linear. Table 4 also shows that the coefficient $\beta(n O O)$ is not exactly equal to 1 and close to linear in the variable $n O O$. Regression between $\beta(n O O)$ and $n O O$ yields the following relationship:

$$
\beta(n O O)=0.062 n O O+0.87
$$

According to Table 4, the constant in the regression between P2LS and P2DoBr, $\alpha(n O O)$, is close to $100 *(1-\beta(n O O))$. Since the average deviation between $\alpha(n O O)$ and $100 *(1-\beta(n O O))$ is equal to -0.20 for all values of nOO less than five, we approximate $\alpha(n O O)$ with the equation:

$$
\alpha(n O O)=99.80-100 * \beta(n O O)
$$

This leads to the following new approximation for the fill rate in a lost sales system, if $n O O<5$ :

$$
P 2 \mathrm{New}=(P 2 \mathrm{DoBr}-\alpha(n O O)) / \beta(n O O) \quad \text { if } n O O<5
$$

with $\beta(n O O)=0.062 n O O+0.87 \quad$ and

$$
\alpha(n O O)=99.80-100 * \beta(n O O)
$$


For experiments with $n O O \geq 5$ we use the observation, illustrated by Figure 3, that for a specific value of $c_{L+R}$ an almost linear relationship was found between P2BO and P2LS. This was found to hold as well for all other values of $c_{L+R}$. Therefore again a regression procedure is performed which yields values for the coefficients $\alpha^{\prime}\left(c_{L+R}\right)$ and $\beta^{\prime}\left(c_{L+R}\right)$ for different values of $c_{L+R}$. An important element here is that $\beta^{\prime}\left(c_{L+R}\right)$, the slope of the regression between P2BO and P2LS, is not a linear function of $c_{L+R}$, but rather an exponential function. If we do regression between $\ln \left(\beta^{\prime}\left(c_{L+R}\right)\right)$ and $\ln \left(c_{L+R}\right)$, we find the following equation, with $\mathrm{R}^{2}$-adjusted $=0.963$ :

$$
\ln \left(c_{L+R}\right)=-0.552 \ln \left(\beta^{\prime}\left(c_{L+R}\right)\right)+0.279
$$

The constant in the regression between P2BO and P2LS, $\alpha^{\prime}\left(c_{L+R}\right)$, is derived in a similar way as described above for the situation with $n O O<5$, enabling us to approximate this constant with the following equation:

$$
\alpha^{\prime}\left(c_{L+R}\right)=101.72-100 * \beta^{\prime}\left(c_{L+R}\right)
$$

This leads to the following new approximation for the fill rate in a lost sales system, if $n O O \geq 5$ :

$$
P 2 N e w=\left(P 2 B O-\alpha^{\prime}\left(c_{L+R}\right)\right) / \beta^{\prime}\left(c_{L+R}\right) \quad \text { if } n O O \geq 5
$$

with $\quad \beta^{\prime}\left(c_{L+R}\right)=c_{L+R}^{-0.552} e^{0.279} \quad$ and

$$
\alpha^{\prime}\left(c_{L+R}\right)=101.72-100 * \beta^{\prime}\left(c_{L+R}\right)
$$

The new approximation, as described in (7) and (8), is tested with a new set of experiments. For this purpose we randomly generated 100 inventory systems. Next, in each inventory system we varied the safety stock from zero to the level where a fill rate of $99 \%$ was reached. This resulted in 3130 simulation experiments, for which we determined P2LS and then used the new approximation P2New. The parameters in the 100 random inventory systems were drawn from continuous uniform distributions on the average demand (between 1 and 10), the variance to 
mean ratio (between 0,1 and 10), the case pack size equal to $\lceil a \mu\rceil$ (with $a$ between 0.1 and 10 ), the lead-time (discrete uniform between 1 and 20) and the review period (discrete uniform between the values 1 and 2).

To evaluate the new approximation (P2New) we determine the average and standard deviation of the approximation error and compare it with the performance of the three other approximations. Table 5 reports these measures for the 3130 simulation experiments described above. The results show that the new approximation performs very well. The average approximation error for $\mathrm{P} 2 \mathrm{New}$ is equal to $0.28 \%$ with a standard deviation equal to $0.45 \%$.

Please put Table 5 here.

The performance of the new approximation for this test bed can also be shown with the graphs showing both the four approximations and the simulated fill rate of the lost sales system.

Please put Figure 5 here.

\section{Conclusions and future research}

While several textbooks suggests that the lost sales model can be treated as a backorder model as long as the service level is high, this paper has shown that even with high target service levels the backorder model can seriously overestimate the amount of safety stock needed. The safety stock is particularly overestimated if the relative demand uncertainty during lead-time and review period is small and/or the number of outstanding orders is large. Especially in these situations as well as in situations with a low target service level, the new approximation developed in this paper is very valuable. The new approximation for the (R,s,nQ)-policy in a lost sales inventory system performs very well: the average approximation error is $0.28 \%$ and the standard deviation of the approximation error is $0.45 \%$. Since the approximations are very fast, this result enables inventory controllers dealing with a lost sales inventory system to set safety stocks in accordance with the target service level set by their management in an effective way.

Although our approximation performs well over a very wide set of parameters, the results should only be applied in an environment where the (R,s,nQ)-policy is close to optimal. Bijvank 
(2009) showed that indeed this policy is close to optimal in many environments, while Zipkin (2008) identified some regions where it is not close to optimal. Future research is needed to further identify the regions where the (R,s,nQ)-policy is close to optimal.

\section{References}

[1] Aardal, K., Jonsson, O., Jonsson, H., 1989. Optimal inventory policies with service-level constraints. Journal of the Operational Research Society. 40, 65-73.

[2] Adan, I.J.B.F., Eenige M.J.A. van, Resing J.A.C., 1995. Fitting discrete distributions on the first two moments. Probability in the Engineering and Informational Sciences 9, 623632.

[3] P. Berling, Marklund, J., 2006. Heuristic Coordination of Decentralized Inventory Systems Using Induced Backorder Costs, Production and Operations Management 15 (2), 294-310.

[4] Bijvank, M., 2009. Service Inventory Management. Solution techniques to inventory systems without backorders. PhD-thesis, Vrije Universiteit Amsterdam, The Netherlands.

[5] Ehrhardt, R., 1979. The power approximation for computing $(\mathrm{s}, \mathrm{S})$ inventory policies. Management Science. 25 (8), 777-786.

[6] Ehrhardt, R., Mosier, C., 1984. A Revision of the Power Approximation for Computing (s, S) Policies. Management Science, 30 (5), 618-622.Gruen, T., D. Corsten, S. Bharadwaj. 2002. Retail Out-of-stocks: A Worldwide Examination of Extent, Causes and Consumer Responses. Grocery Manufacturers of America, Washington, D.C.

[7] Hadley, G., Whitin, T.M., 1963. Analysis of inventory systems. Prentice-Hall, Englewood Cliffs, New Jersey.

[8] Hill, R.M., 1992. Numerical analysis of a continuous-review lost-sales inventory model where two orders may be outstanding. European Journal of Operational Research 62, 1126.

[9] Hill, R.M., 1994. Continuous review lost sales inventory models where two orders may be outstanding. International Journal of Production Economics, 35, 313-319.

[10] Johansen, S.G., and Hill, R.M., 2000. The (r,Q) control of a periodic-review inventory system with continuous demand and lost sales. International Journal of Production Economics. 68 279-86.

[11] Kapalka, B.A., Katircioglu, K., Puterman, M.L., 1999. Retail inventory control with lost sales service constraints, and fractional lead times. Production and Operations Management, 8, 393-408.

[12] Karlin, S., H. Scarf, 1958. Inventory models of the Arrow-Harris-Marschak type with time-lag. K. Arrow, S. Karlin, eds. Studies in the Mathematical Theory of Inventory and Production. Stanford University Press, Stanford, CA.

[13] Law, A.M., Kelton W.D., 2000. Simulation modeling and analysis (third ed.). Boston: McGraw-Hill.

[14] Mohebbi, E. and Posner, M.J.M., 1998. A continuous-review inventory system with lost sales and variable lead time. Naval Research Logistics, 45, 259-278. 
[15] Morton, T., 1969. Bounds on the solution of the lagged optimal inventory equation with no demand backlogging and proportional costs. SIAM Rev. 11, 572-576.

[16] Nahmias, S., 1979. Simple approximations for a variety of dynamic leadtime lost-sales inventory models. Operations Research 27, 904-924.

[17] Schneider, H., Ringuest, J.L., 1990. Power approximation for computing (s,S) policies using service level. Management Science. 36 (7), 822-834.

[18] Tijms, H.C., Groenevelt, H., 1984. Simple approximations for the reorder point in periodic and continuous review $(\mathrm{s}, \mathrm{S})$ inventory systems with service level constraints. European Journal of Operational Research. 17, 175-190.

[19] Van Donselaar, K., De Kok, T., Rutten, W., 1996. Two replenishment strategies for the lost sales inventory model: a comparison. International Journal of production Economics, 46-47, 285-295.

[20] Van Donselaar, K.H., Broekmeulen, R.A.C.M., 2009. Setting safety stocks for perishable items in a periodic review inventory system with discrete demand, positive lead-time, lost sales and fixed case pack size, BETA working-paper nr. 301, Eindhoven University of Technology, The Netherlands.

[21] Silver, E.A., Pyke, D.F., Peterson, R., 1998. Inventory management and production planning and scheduling. John Wiley \& Sons, New York, third edition

[22] Zipkin, P., 2008. Old and new methods for lost-sales inventory systems. Operations research 56(5) p. 1256-1263. 